\title{
Researching creativity and wellbeing: Interdisciplinary perspectives
}

\author{
Frederic Kiernan · Jane W. Davidson · Lindsay G. Oades
}

\section{Introduction}

This special issue on creativity and wellbeing represents the outcome of a collaboration between the International Journal of Wellbeing and the Creativity and Wellbeing Hallmark Research Initiative (CAWRI) at the University of Melbourne. It includes contributions from academics associated with CAWRI as well as those in our local and international network. The volume appears at a time when these two concepts, and the relationship between them, have been brought to attention in a range of contexts by extraordinary global events. The COVID-19 pandemic, for example, has had disastrous health and wellbeing impacts and has led to stay-at-home orders and extensive lockdowns which have "changed everyday life for the masses, in an unprecedented manner" (Warren \& Bordoloi, 2020, p. 1). Insofar as creativity involves adaptive behavior that emerges in response to interruptions to previously successful routines and habits (Joas, 1996), 2020 has been the year of creativity par excellence. But the disruptive impact of COVID-19 has also destroyed or damaged many creative social products generated by those old routines and habits, meaning that routines and habits, and not just interruptions or impasses, can also be pathways to creativity (Dalton, 2004). The events of 2020 should therefore give us pause to consider the meaning of the term "creativity" and to reflect on the potential role of creativity in cultivating and supporting wellbeing.

The purpose of this special issue is to consider the relationship between creativity and wellbeing from a range of disciplinary perspectives in order to illuminate and better understand this relationship. Because of this disciplinary variety, theoretical frameworks and methodological approaches are drawn from different traditions of creativity research. Modern creativity research is usually said to have started in 1950 with the publication of Guilford's 1949 presidential address to the American Psychological Association, titled "Creativity" (Guilford, 1950), although creativity was a key aspect of much early sociological thinking, as in, for example, Weber's notion of charismatic leadership and Marx's idea of the active and creative subject (Chan, 2016). Nevertheless, creativity research was mostly marginalized in sociology until the late twentieth century, with the field being dominated by psychological and philosophical approaches (Cropley, 2011; Domingues, 2000). But theoretical links between creativity and wellbeing find roots even in the seventeenth-century writings of Francis Bacon and René Descartes, two of the early founders of modern science, who viewed creativity as involving the harnessing of the forces of nature for the betterment of the human condition (Cropley, 2011). Creativity has also been understood in different ways in different cultures, with some conceptions of creativity emphasizing "vertical" or process-oriented aspects, and others emphasizing "horizontal" aspects associated with novelty and rupture (Celik \& Lubart, 2016). Similarly, definitions of wellbeing have varied greatly, with some emphasizing the individual experience of pleasure, life satisfaction and self-realization, while others are tied to the collective 
experiences of social groups and the interrelationships between people, land, culture, and spirituality (Dodge et al., 2012; Oades \& Heazlewood, 2017). The links between creativity and wellbeing, and their cognate terms and concepts in other languages, thus have a long history in scholarly and cultural thought.

Scholarly literature on creativity often distinguishes between "Big-C" and "little-c" creativity. "Big-C" creativity refers to eminent-level creativity: the work of famous, unambiguous creators such as Pablo Picasso and Albert Einstein. This idea is grounded in older romantic and typically Western conceptions of creativity, which have been guided by the construction of the lone creative genius, someone said to be in possession of greater amounts of creativity than others, and whose creative work is said to require some degree of separation from society (Montuori \& Purser, 1995). On the other hand, "little-c" creativity refers to the informal, everyday potential for creativity that all people possess and is grounded in the idea that creativity is a quality essential to human development and is a vital component of a healthy and happy life (Richards, 2018; see also Kaufman \& Beghetto, 2009, who added "Pro-c" and "mini-c" to this model). This shift in creativity research away from the lone creative genius to the everyday creative practices of regular people was also reflected in the "Four P" framework for creativity person, product, process, press - which was widely used in the second half of the twentieth century to understand the different dimensions of creativity (Runco \& Kim, 2011). The fourth P, "press" (i.e. the pressure of the environment), of this framework helped to bring creativity research into domains such as business, education and manufacturing, which were previously viewed as irrelevant to creativity research (Cropley, 2011). This has also helped to position creativity as an increasingly important concept in the burgeoning field of wellbeing research (Basadur \& Basadur, 2011; Krippner, 2011; Csikszentmihalyi, 2014; Gillam, 2018; Barker, 2019).

Over the last decade, a variety of new units of analysis in creativity research have been proposed. Such propositions include, for example, the idea that creativity can be viewed as a socio-cultural act (Glăveanu, 2015), which may be spread across and between multiple actors and elements (Glăveanu, 2014; Clarke \& Doffman, 2017). Other scholars have suggested that creativity is not a domain-general phenomenon (Baer, 2016), but rather, something that varies according to the way it is expressed, and which is therefore measured against domain specific standards and local criteria (Chan, 2016; Kaufman et al., 2017; Kaufman \& Sternberg, 2019). These developments in creativity research have opened up new possibilities for understanding and applying the concept of creativity in a seemingly limitless number of contexts, but they also risk dissolving the idea of creativity into an amalgamation of related elements which may, in turn, undermine its explanatory power. Thus, as the field of creativity studies develops in exciting directions, new challenges also emerge, which implicate our understanding of what and where creativity is, and how it relates to wellbeing.

\section{The contents of the special issue}

Against this background, this special issue presents eight articles that each address current challenges in creativity and wellbeing research. Two of these articles examine the link between creativity and wellbeing from a theoretical perspective. Nicolas B. Verger and Raffi Duymedjian examine the creativity of romantic relationships at the dyadic level, where "dyad" is defined as a prolonged interaction between two individuals, taking the couple as a single unit. Their approach treats romantic creativity as an observable, quantifiable, yet non-product-hierarchic phenomenon, and they propose an original theoretical framework for explaining how romantic creativity and wellbeing may be linked. They argue that romantic creativity can take the form of a dyadic process, in which the dynamics of discovery and self-expansion can be explored by one 
or both members of the dyad, thereby taking the relationship in new and meaningful directions. Addressing the theoretical link between creativity and wellbeing from a different angle, Frederic Kiernan's article argues that the history and sociology of emotion (Scheer, 2012) and the sociology of creativity (Chan, 2016) can coalesce in a new framework for understanding emotion as creative practice. Kiernan's study sets out four categories of emotion as creative practice-a) emotion as institutionalized cultural practice; b) emotion as cultural edgework; c) emotion as cultural transcendence; and d) emotion as cultural transformation-to argue that emotions themselves do creative work. He thereby provides a new explanation for the role of emotion in generating social and historical change and forges new theoretical links between creativity and wellbeing from a sociological perspective.

Two of the articles consider the link between creativity and wellbeing by examining musicmaking practices. Andrew Geeves, Samuel Jones, Jane W. Davidson and John Sutton consider in their article the perspective of the performing musician, who is presently underrepresented in research on the relationship between music and wellbeing. Using the case study of Australian pop/rock band Cloud Control, their article investigates how the performing practices of musicians on tour impact their wellbeing, and they argue that the concepts of "performance headspace" and "connection with audience" can serve as explanatory themes for the link between creativity and wellbeing for performing musicians. Taking a different approach, Grace Thompson, Melissa Raine, Susan M. Hayward and Hannah Kilpatrick question in their article how music-making workshops can be made more autism-friendly. Their research gathers community perspectives on this issue to argue that environmental and social factors work together to create a sense of safety and inclusion for autistic participants, and that a welcoming atmosphere and acceptance of diversity are expected from the workshop facilitator and group members.

Three of the articles examine the link between creativity and wellbeing specifically for women. Donna Lyon, Shannon Owen, Margaret S. Osborne, Khandis Blake and Bruna Andrades investigate in their article how the combination of creative writing and non-contact boxing can facilitate the recovery journeys of women survivors of childhood sexual abuse towards posttraumatic growth. Their article reports on a series of workshops named Left/Write//Hook which used a range of analytical and creative techniques to understand how writing and boxing are uniquely positioned to benefit the workshop participants. They draw on ideas and techniques from dance movement therapy, kinesthetics, psychology and other areas to suggest that different modes of cognition (language-based and embodied) and the creative activities through which these were realized in the workshops contributed to participants' recovery journeys and supported their wellbeing in different and crucial ways.

Lila Moosad and Cathy Vaughan examine in their article the link between creativity and wellbeing for a group of 18 older women who participated in a photography project called 500 Strong. The project involved more than 400 women aged over 50 from Melbourne and regional Victoria, Australia, who each posed nude in photographs in order to challenge negative stereotypes about women's ageing as a time of decline and loss. This qualitative study examined the experiences and motivations of the participants, finding that the link between creativity and wellbeing in this context could be explained by the concepts of care, collaboration and critique. The third article to address women's creativity and wellbeing is by Mahima Kalla and Margaret Simmons, who examine how these concepts intersect in the experiences of a group of women suffering from Chronic Fatigue Syndrome. This medical condition is poorly understood, and because of this it has frequently been dismissed as an untreatable psychological issue, leading to inadequate care and to patients feeling isolated and neglected. The authors report that the illness 
also disproportionately affects women rather than men at an approximate ratio of 4:1. Because of the illness's ambiguous status in medical discourse and its unclear aetiology, the researchers adopt a narrative research technique called poetic representation, casting the participants' own words into poetic forms. The authors thus interpret their data not just as researchers but also as poets, thereby rethinking the role of the researcher in creativity and wellbeing research by using the medium of poetry to communicate different aspects of the participants' illness experience.

Broadening the conceptual scope somewhat, Amanda E. Krause, Anya Lloyd-Smith and John Hajek examine the intersection of creativity and wellbeing in migrant communities in Australia through a study of community language radio. Their research focuses on the practices of presenters at Australia's largest community language radio station, 3ZZZ, and their article argues that community language radio plays a crucial role in supporting wellbeing of both individuals and communities by providing an accessible and adaptable outlet for creative expression. The article highlights how the radio programs provide a form of creative cultural and language maintenance which contributes positively to wellbeing in the Australia migrant context.

\section{Conclusion}

This special issue thus advances the field of creativity and wellbeing research by exploring linkages between these concepts from a range of disciplinary perspectives. It proposes new theoretical frameworks and concepts linking creativity and wellbeing in romantic relationships and in emotion, and it considers the role of music making for wellbeing from the perspectives of performing musicians as well as autistic people. It gives particular attention to the experiences of women, as survivors of abuse, as sufferers of chronic fatigue syndrome and as empowered agents in the ageing process, and it also gives attention to community language radio as a creative pathway towards wellbeing for migrant communities in Australia. The special issue also flags numerous potential avenues for further investigation, and we, as the editors, look forward to seeing where these exciting developments in the field will lead.

\section{Authors}

Frederic Kiernan

The University of Melbourne

kiernanf@unimelb.edu.au

Jane W. Davidson

The University of Melbourne

Lindsay G. Oades

The University of Melbourne

\section{Publishing Timeline}

Received 2 September 20202020

Accepted 26 November 2020

Published 17 December 2020

\section{References}

Baer, J. (2016). Domain specificity of creativity. Elsevier.

Barker, S. (2019). Mental wellbeing and psychology: The role of art and history in self discovery and creation.

Routledge. https://doi.org/10.4324/9780429434310 
Basadur, M., \& Basadur, T. (2011). Attitudes and creativity. In M. A. Runco \& S. R. Pritzker (Eds.), Encyclopedia of creativity (2nd ed, pp. 85-95). Elsevier. https://doi.org/10.1016/B978-0-12-3750389.00017-0

Celik, P., \& Lubart, T. (2016). When east meets west. In V. P. Glăveanu (Ed.), The Palgrave handbook of creativity and culture research (pp. 37-55). Palgrave Macmillan. https://doi.org/10.1057/978-1-13746344-9_3

Chan, J. (2016). Creativity and culture: A sociological perspective. The Palgrave handbook of creativity and culture research, 639-660. https://doi.org/10.1057/978-1-137-46344-9_31

Clarke, E. F., \& Doffman, M. (Eds.). (2017). Distributed creativity: Collaboration and improvisation in contemporary music. Oxford University Press. https://doi.org/10.1093/oso/9780199355914.001.0001

Cropley, A. (2011). Definitions of creativity. In M. A. Runco \& S. R. Pritzker (Eds.), Encyclopedia of creativity (2nd ed., pp. 358-68). Elsevier. https://doi.org/10.1016/B978-0-12-375038-9.00066-2

Csikszentmihalyi, M. (2014). Flow and the foundations of positive psychology: The collected works of Mihaly Csikszentmihalyi. Springer. https://doi.org/10.1007/978-94-017-9088-8

Dalton, B. (2004). Creativity, habit, and the social products of creative action: Revising Joas, incorporating Bourdieu. Sociological Theory, 22(4), 603-622. https://doi.org/10.1111/j.0735-2751.2004.00236.x

Dodge, R., Daly, A. P., Huyton, J., \& Sanders, L. D. (2012). The challenge of defining wellbeing. International Journal of Wellbeing, 2(3), 222-235. https://doi.org/10.5502/ijw.v2i3.4

Domingues, J. M. (2000). Creativity and master trends in contemporary sociological theory. European Journal of Social Theory, 3(4), 467-484. https://doi.org/10.1177/13684310022224903

Gillam, T. (2018). Creativity, wellbeing and mental health practice. Palgrave Macmillan. https://doi.org/10.1007/978-3-319-74884-9

Glăveanu, V. P. (2014). Distributed creativity: Thinking outside the box of the creative individual. Springer. https://doi.org/10.1007/978-3-319-05434-6

Glăveanu, V. P. (2015). Creativity as a sociocultural act. The Journal of Creative Behavior, 49(3), $165-180$. https://doi.org/10.1002/jocb.94

Guilford, J. P. (1950). Creativity. American Psychologist, 5, 444-454. https://doi.org/10.1037/h0063487

Joas, H. (1996). The creativity of action (J. Gaines \& P. Keast, Trans.). University of Chicago Press.

Kaufman, J. C., \& Beghetto, R. A. (2009). Beyond big and little: The Four C model of creativity. Review of General Psychology, 13(1), 1-12. https://doi.org/10.1037/a0013688

Kaufman, J. C., Glǎveanu, V. P., \& Baer, J. (Eds.). (2017). The Cambridge handbook of creativity across domains. Cambridge University Press. https://doi.org/10.1017/9781316274385

Kaufman, J. C., \& Sternberg, R. J. (2019). The Cambridge handbook of creativity. Cambridge University Press. https://doi.org/10.1017/9781316979839

Krippner, S. (2011). Altered and transitional states. In M. A. Runco \& S. R. Pritzker (Eds.), Encyclopedia of creativity (2nd ed., pp. 33-39). Elsevier. https://doi.org/10.1016/B978-0-12-375038-9.00008-X

Montuori, A. \& Purser, R. (1995). Deconstructing the lone genius myth: Toward a contextual view of creativity. Journal of Humanistic Psychology 35(3), 69-112. https://doi.org/10.1177/00221678950353005

Oades, L., \& Heazlewood, F. (2017). Wellbeing language $\mathcal{E}$ definitions guide. Mental Health Commission of NSW.

Richards, R. (2018). Everyday creativity and the healthy mind: Dynamic new paths for self and society. Palgrave Macmillan. https://doi.org/10.1057/978-1-137-55766-7

Runco, M. A., \& Kim, D. (2011). The Four Ps of creativity: Person, product, process, and press. In M. A. Runco \& S. R. Pritzker (Eds.), Encyclopedia of creativity (2nd ed., pp. 534-537). Elsevier. https://doi.org/10.1016/B978-0-12-375038-9.00102-3

Scheer, M. (2012). Are emotions a kind of practice (and is that what makes them have a history)? A Bourdieuian approach to understanding emotion. History and Theory: Studies in the Philosophy of History, 51(2), 193-220. https://doi.org/10.1111/j.1468-2303.2012.00621.x

Warren, M. A., \& Bordoloi, S. (2020). When COVID-19 exacerbates inequities: The path forward for generating wellbeing. International Journal of Wellbeing, 10(3) Special Issue: COVID-19 and Wellbeing, 1-6. https://doi:10.5502/ijw.v10i3.1357 